\title{
PENDEKATAN OTOMATISASI EVALUASI KUALITAS KELENGKAPAN PADA INFORMASI GEOSPASIAL
}

\author{
Ari Sutanto ${ }^{1,2, *}$, Trias Aditya $^{1}$ \\ ${ }^{1}$ Program Studi Magister Teknik Geomatika, Fakultas Teknik, Universitas Gadjah Mada \\ ${ }^{2}$ Badan Informasi Geospasial \\ *Penulis Korespondensi : ari.sutanto@mail.ugm.ac.id
}

\begin{abstract}
Abstrak. Program percepatan penyediaan informasi geospasial skala besar harus diimbangi dengan percepatan proses evaluasi kualitas. Evaluasi kualitas kelengkapan informasi geospasial skala besar masih dilakukan secara visual. Evaluasi dilakukan dengan pencocokan terhadap sumber data berupa data mozaik orthophoto. Evaluasi secara visual memerlukan waktu lebih lama dan tidak akan mampu mengimbangi kegiatan percepatan penyediaan informasi geospasial skala besar. Penelitian ini bertujuan untuk mencari pendekatan evaluasi kualitas kelengkapan data spasial yang terstandar dan berjalan secara otomatis. Evaluasi dilakukan terhadap layer bangunan berbentuk poligon yang merupakan salah satu produk informasi geospasial dasar skala besar. Kelengkapan data diukur dari jumlah kelebihan data (commission) dan kekurangan data (omission). Pendekatan evaluasi kualitas dilakukan dengan pembangunan tools deteksi kelengkapan (omission dan commission). Tools deteksi menggunakan metode pencocokan pada level unsur dengan membandingkan seluruh data uji terhadap referensi. Ada 4 skenario yang digunakan dalam menguji kemampuan tools evaluasi berdasarkan bentuk data pembanding dan matching option. Hasil penelitian ini menunjukan bahwa pembanding poligon memperoleh true commission dan true omission yang lebih baik dibanding menggunakan pembanding point (radius 2,5 meter) pada opsi pencocokan "intersect" dan "Have Their Center In". Pendekatan evaluasi kelengkapan secara otomatis masih memiliki kesalahan deteksi omission dan commission. Untuk mendukung percepatan pengadaan informasi geospasial skala besar, diusulkan prosedur evaluasi kualitas semi otomatis yang menggabungkan deteksi otomatis dan validasi visual untuk memperoleh hasil evaluasi kualitas kelengkapan yang lebih baik. Kata Kunci: otomatisasi; evaluasi kualitas; elemen kelengkapan; informasi geospasial skala besar
\end{abstract}

\begin{abstract}
The program of geospatial information provision acceleration in large scale must be offset by the acceleration of quality evaluation process. The quality evaluation of large scale geospatial information completeness is still conducted visually. The evaluation is conducted by matching the data sources in the form of orthophoto mosaic data. Visual evaluation needs quite a long time and it will not be capable of offsetting the acceleration activity of large scale geospatial information provision. This research aims to find out the approach of standardized qualitiy evaluation of spatial data completeness and runs automatically. The evaluation was conducted on building layer in the form of polygon which is one of the products of large scale basic geospatial information. The data completeness was measured from the total of data excess data (commission) and lack of data (omission). Quality evaluation approach was conducted with building of completeness detection tools (omission and commission). Detection tools used matching method at component level by comparing all test data towards the reference. There were 4 scenarios used in testing the ability of evaluation tools based on comparative data form and matching option. The results of this research show that polygon comparator obtains true commission and better true omission compared by using point comparator (radius 2,5 meter) at matching option "intersect" and "have their center in". The completeness evaluation approach automatically still has mistake of omission detection and commission detection. To support the acceleration of large scale geospatial information provision, semi-automatic quality evaluation procedure is proposed which combines automatic detection and visual validation to obtain better result of completeness quality evaluation.
\end{abstract}

Keywords: automation; quality evaluation; completeness element; large scale geospatial information

\section{PENDAHULUAN}

Kebutuhan informasi geospasial (IG) skala besar yang semakin tinggi dan cepat, mendorong pemerintah Indonesia untuk mempercepat penyediaan informasi geospasial skala besar di seluruh wilayah Indonesia. Penyediaan informasi geospasial dasar skala besar di seluruh wilayah Indonesia menjadi salah satu target prioritas 
pembangunan kewilayahan dalam RPJMN 20202024 (Kemenkumham RI, 2020). Hal ini, menuntut penyelenggara informasi geospasial pemerintah maupun swata untuk menyusun strategi pemenuhan IG skala besar dalam upaya percepatan penyediaan data geospasial.

Perpres Satu Data Indonesia nomor 39 tahun 2019 menyatakan bahwa "ketersediaan data yang berkualitas harus mudah diakses dan dibagipakaikan". Perpres ini merupakan salah satu dasar utama penjaminan kualitas dalam penyediaan data geospasial. Percepatan penyediaan informasi geospasial skala besar, harus diimbangi dengan penjaminan informasi kualitasnya. Undang-undang Nomor 4 Tahun 2011 tentang Informasi Geospasial, mewajibkan penyelenggara Informasi Geospasial melakukan penjaminan dan memberitahukan kualitas setiap IG yang diselenggarakannya. Informasi kualitas sangat penting dalam ketepatan penggunaan dan pemanfaatan IG. Jantung dari sebuah sistem informasi geospasial adalah database spasial yang handal dan berorientasi pengguna (Ahmed, 2020). Saat ini, informasi geospasial yang dibagipakaikan masih banyak yang tidak disertai dengan informasi kualitas, hal ini dapat menyebabkan pengguna data salah dalam mengimplementasikan pemanfaatan informasi geospasial tersebut.

Kendala yang dihadapi dalam proses penjaminan kualitas adalah belum adanya data pembanding untuk evaluasi kelengkapan dalam bentuk data vektor skala besar. Data pembanding satu satunya yang tersedia adalah sumber data produksi peta Rupabumi Indonesia berupa foto udara. Proses pelaksanaan evaluasi kualitas kelengkapan informasi geospasial skala besar masih dilakukan secara manual (visual cek) terhadap sumber data (foto udara). Proses manual tentu memerlukan waktu lebih lama. Hal tersebut menjadi hambatan dalam program percepatan pemenuhan informasi geospasial dasar skala besar. Percepatan pengadaan informasi geospasial skala besar di Indonesia perlu diimbangi dengan pendekatan metode otomasi dalam mengevaluasi kualitas data spasial sehingga produk percepatan informasi geospasial skala besar tersebut tetap terjamin kualitasnya.

Wan dkk., (2015) menyatakan bahwa "ada kebutuhan mendesak untuk mengembangkan sistem generik otomatis atau sistem otomatis dalam evaluasi kualitas data spasial". Seiring perkembangan teknologi terkini, evaluasi kualitas lebih mengarah pada pada metode pendekatan yang lebih otomatis dengan tujuan standarisasi proses dan mengurangi resiko (Jakobsson dkk., 2010). Devillers dkk. (2007) melakukan penelitian tentang desain tools yang dapat mengelola informasi kualitas dan mendukung pengguna dalam menilai kualitas data. Informasi kualitas data yang heterogen dikelola dalam tools yang menyediakan fungsi untuk mendukung pengguna dalam melakukan penilaian fitness for use sebuah dataset serta menggabungkan konsep dari Geographic Information System (GIS) dan business intelegence. Pendekatan metode evaluasi kualitas dengan alur kerja dapat meningkatkan interoperabilitas data geospasial dan kecerdasan fungsi berbasis GIS berdasarkan metadata terstandarisasi, algoritma kualitas data, dan alat bantu visual dari informasi kualitas data (Shi dkk., 2015).

Penelitian ini bertujuan untuk menyusun pendekatan otomatis evaluasi kualitas berdasarkan standar kualitas data spasial. Uji coba pendekatan evaluasi kelengkapan dilakukan terhadap layer bangunan (poligon) yang merupakan produk informasi geospasial dasar skala besar. Pendekatan teknis menggunakan konsep pencocokan dengan obyek referensi menggunakan geoprocessing tools dalam platform GIS.

\section{METODOLOGI}

Penelitian meliputi tahapan persiapan data, penyusunan geoprocessing tools dengan skenario, tahap uji coba tools deteksi kelengkapan, analisis hasil dan rekomendasi prosedur evaluasi kualitas kelengkapan.

Persiapan data meliputi data uji berupa layer bangunan, bersumber dari dataset peta RBI Skala 1:5.000, NLP 1209-4212B wilayah Kab. Bogor yang diproduksi Badan Informasi Geospasial tahun 2016. 
Data referensi berupa mosaik orthophoto, bersumber dari foto udara yang merupakan data dasar pemetaan RBI skala 1:5.000 wilayah Kab. Bogor akuisisi tahun 2014. Data pembanding analisis berupa hasil digitasi on-screen dan deteksi obyek bangunan menggunakan deep learning terhadap foto udara.

Lokasi sampel berada pada sebagian wilayah Kabupaten Bogor dengan luasan $1 \mathrm{~km}^{2}$. Lokasi sampel dipilih berdasarkan keberagaman tingkat kepadatan bangunan agar dapat memberikan gambaran pada hasil implementasi tools otomasi. Lokasi penelitian disajikan pada Gambar 1.

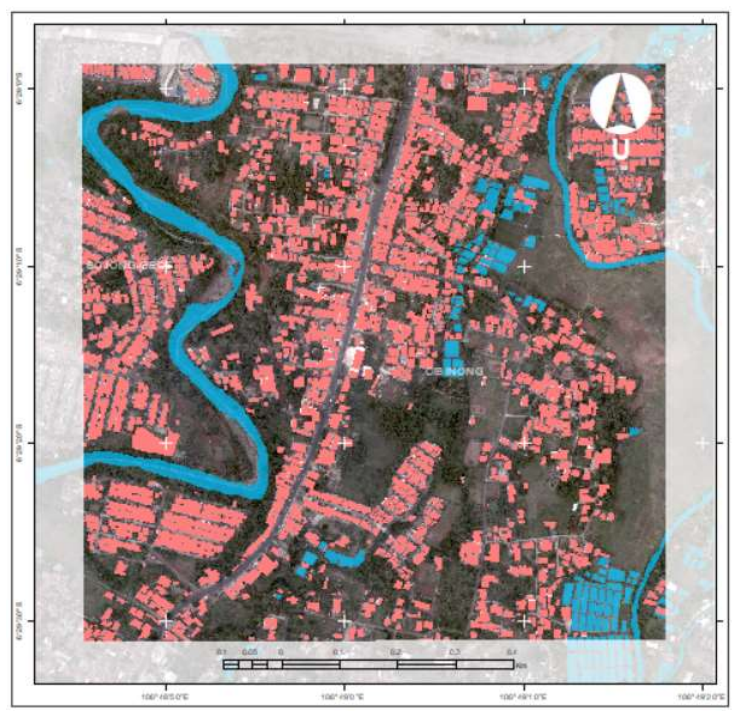

Gambar 1. Lokasi sampel penelitian

Pemilihan elemen kualitas untuk evaluasi dataset informasi geospasial (IG) pada penelitian ini menggunakan elemen kualitas kelengkapan dengan sub-elemen Commission dan Omission sesuai dengan (Badan Standar Nasional Indonesia, 2015). Persyaratan kualitas bangunan yang digunakan, mengikuti persyaratan spesifikasi produk basis data geospasial nasional Indonesia sebagai berikut:

Kelengkapan (completeness) adalah ukuran sejauh mana konten data sesuai dengan dunia nyata sesuai dengan pengambilan data, cakupan dataset, dan pada tingkat yang diperlukan (Badan Standar Nasional Indonesia, 2015). Ukuran kualitas yang digunakan dalam mengevaluasi elemen kelengkapan (commission dan omission) adalah error rate. Pada sub-elemen commission, yang dimaksud dengan error rate adalah persentase item yang berlebih pada dataset (rate of excess items), sedangkan error rate pada sub-elemen omission adalah persentase item yang tidak ada (kurang) pada dataset (rate of missing items). Pada spesifikasi produk data IG dari Badan Informasi Geospasial, standar kualitas kelengkapan untuk IG dasar terbagi menjadi 3 (tiga) kelas (Tabel.II.1). kelas A maksimal error rate tidak lebih dari $1 \%$. Umtuk error rate antara $1 \%$ sampai dengan kurang dari $4 \%$ masuk pada kelas $B$, sedangkan error rate yang lebih dari $4 \%$ masuk pada kriteria kelas $C$ (Badan Informasi Geospasial, 2020).

Tabel 1. Kelas kualitas data untuk elemen kelengkapan (Sumber: Spesifikasi produk Data IG (BIG))

\begin{tabular}{cc}
\hline Kelas & Error rate \\
\hline $\mathrm{A}$ & $\leq 1 \%$ \\
$\mathrm{~B}$ & $>1 \%$ dan $\leq 4 \%$ \\
$\mathrm{C}$ & $>4 \%$ \\
\hline
\end{tabular}

Brovelli dan Zamboni (2018) melakukan metode pencocokan tapak bangunan data OSM berdasarkan perbandingan dataset otoritatif. Pencocokan ini dilakukan dengan memeriksa kesamaan bangunan, sehingga dapat dideteksi dan dihitung kelengkapannya. Kelengkapan dapat dihitung melalui operasi standar (Razniewski dan Nutt, 2013). Pencocokan spasial menurut Xavier dkk. (2016) dapat diklasifikasikan sesuai level terjadinya korespondensi, yaitu dilakukan pada tingkat skema, unsur, dan internal. Pencocokan pada tingkat skema merupakan level tertinggi, pencocokan ini terjadi pada model. Pencocokan unsur terjadi pada tingkat obyek dan pencocokan internal terjadi didalam komponen internalnya, contohnya node dalam vertex.

Penelitian Xavier dkk. (2016) juga menjelaskan tentang derajat hubungan yang dapat terjadi pada pencocokan spasial. Derajat hubungan yang terjadi dapat dikelompokan kedalam 3 nilai relasi yaitu relasi 1-1 (satu ke satu), 1-n (satu ke banyak) dan nm (banyak ke banyak).

Dalam evaluasi kualitas kelengkapan, untuk mendapatkan obyek data berlebih (Commission) digunakan metode pencocokan pada level unsur. Pencocokan ini membandingkan seluruh data uji 
terhadap data referensi. Dengan teknik spatial join, data uji digunakan sebagai layer target, kemudian dilanjutkan dengan operasi selection. Selection dilakukan terhadap nilai join $=0$ atau obyek layer uji yang tidak memiliki pasangan yang dinyatakan sebagai commission. Demikian sebaliknya untuk mendapatkan obyek data kurang (omission), perbandingan data uji terhadap data referensi, layer referensi digunakan sebagai layer target. Sehingga obyek layer referensi yang tidak memiliki pasangan atau nilai join $=0$ dinyatakan sebagai omission
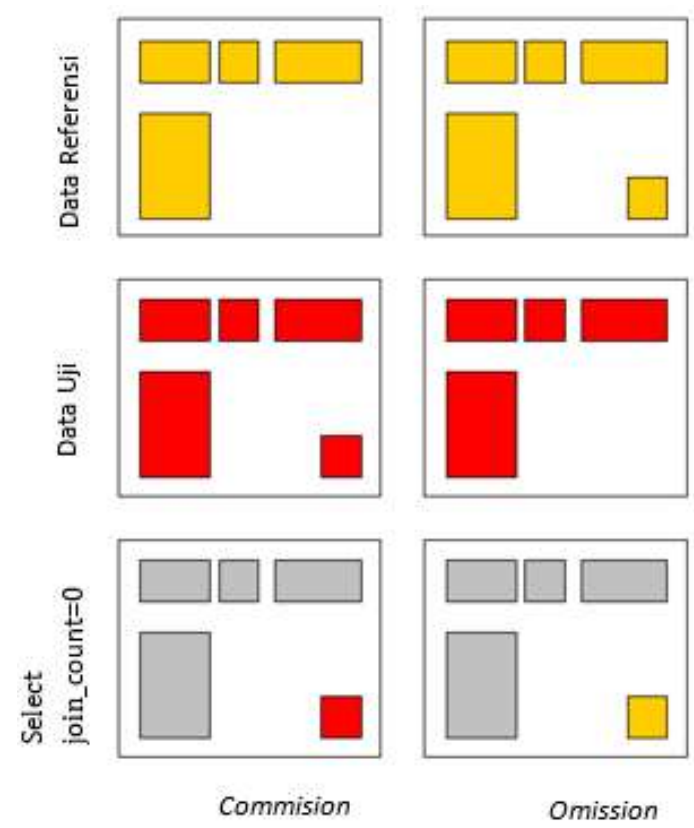

Gambar 2. Omission dan commision pada pencocokan data spasial

ilustrasi dapat dilihat pada Gambar 2.

Shi dkk. (2015) melakukan pendekatan sistem evaluasi kualitas dengan mengeksplorasi hubungan antara informasi kualitas data geospasial dalam penggunaan fungsi GIS. Geoprocessing merupakan seperangkat alat untuk melakukan pemrosesan terhadap data spasial. Pemrosesan dilakukan untuk tujuan menghasilkan turunan data spasial baru. Serangkaian alat geoprocessing dapat dibuat model untuk melakukan pengelolaan dan analisis data spasial. Pada penelitian ini digunakan model builder pada platform ArcGIS. Model builder dalam ArcGIS merupakan bahasa pemrograman visual yang digunakan dalam pembuatan workflow diagram (Dobesova, 2013). Model builder dapat dikelola dan dimodifikasi sesuai tujuan analisis. Model builder dapat digunakan untuk proses otomasi (Perdana dkk., 2012). Bahasa pemrograman visual ini membuat proses pengolahan data spasial menjadi lebih mudah karena mampu mengotomatisasi workflow dan diproses secara bersamaan (Schaller dan Mattos, 2009). Model builder ini dimanfaatkan untuk menyelesaikan tugas evaluasi kualitas secara otomatis.

\section{HASIL DAN PEMBAHASAN}

Evaluasi kualitas data spasial merupakan cara mendapatkan nilai atau tingkat baik buruknya data spasial. Proses mendapatkan nilai kualitas dapat menggunakan pendekatan manual dan otomatis. Penelitian ini mencoba mendapatkan nilai kualitas kelengkapan secara otomatis. Pendekatan evaluasi kualitas secara otomatis dilakukan untuk mengurangi campur tangan manusia dalam mengeksekusi tugas analitik secara spesifik dan berulang. Proses sepenuhnya dikendalikan oleh program yang berjalan dalam komputer. Parameter harus ditentukan dalam sebuah program untuk mendapatkan keluaran. Parameter pemrosesan untuk mendapatkan keluaran dari evaluasi kualitas kelengkapan masih beragam. Hal ini menjadi bahasan pokok dalam penelitian ini untuk mencari parameter terbaik dalam pembangunan sistem evaluasi kelengkapan secara otomatis.

Evaluasi kelengkapan dilakukan untuk mendapatkan nilai kesalahan data lebih (commission) dan data kurang (omission). Implementasi otomasi dilakukan dengan membuat model builder dan script Python pada perangkat lunak ArcGIS. Model dibuat untuk mendeteksi kesalahan data lebih dan data hilang. Model yang dibangun memerlukan parameter yang perlu diujicoba untuk mendapatkan hasil terbaik. Algoritma yang dibangun dalam model adalah fungsi aggregate polygons, spatial join, select dan get count. Pembuatan tools otomatis untuk deteksi obyek omission dan commission menggunakan model builder seperti disajikan pada Gambar 3. 


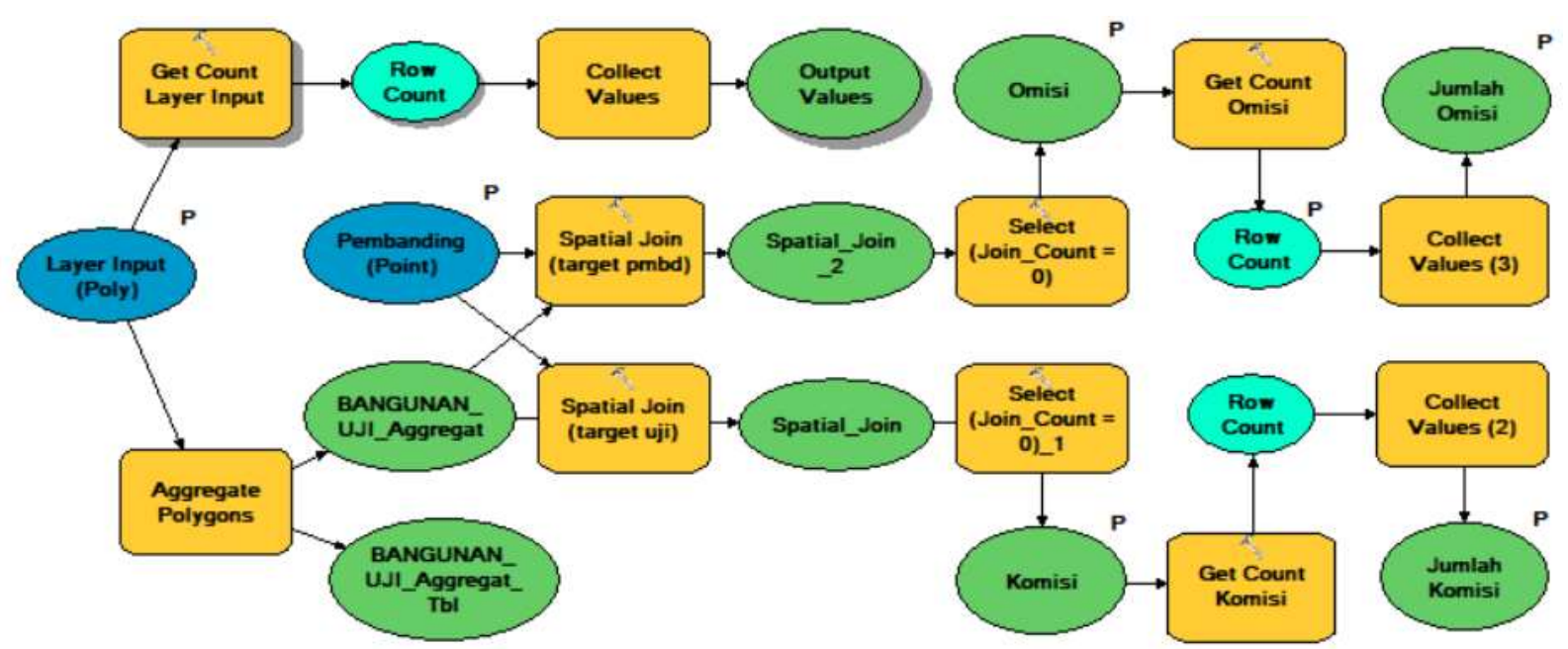

Gambar 3. Model Builder untuk mendapatkan Omission dan Commission

\section{Deteksi kelengkapan secara visual}

Sebelum menjalankan proses deteksi kelengkapan secara otomatis, dilakukan terlebih dahulu deteksi kelengkapan secara visual. Deteksi kelengkapan secara visual dilakukan untuk mendapatkan hasil omission dan commission acuan. Visual cek merupakan metode manual yang dilakukan dengan mencocokkan layer bangunan dengan kenampakan obyek bangunan pada foto udara. Pengecekan secara visual dilakukan terhadap seluruh cakupan data dengan mengidentifikasi jumlah item yang kurang (omission) merupakan obyek bangunan yang belum dilakukan plotting dan item berlebih (commission) merupakan obyek bangunan yang dianggap salah plotting. Hasil pengecekan ini akan menjadi acuan dalam pengujian kemampuan tools otomasi. Pengecekan dilakukan terhadap 2480 item/obyek bangunan pada data uji dengan luas wilayah $1 \mathrm{~km}^{2}$. Wilayah penelitian merupakan area dengan kepadatan bangunan bervariasi dari jarang

Tabel 2. Kelas kualitas data untuk elemen kelengkapan dengan pengecekan visual

\begin{tabular}{clc}
\hline No & Komponen Kualitas Kelengkapan & $\begin{array}{c}\text { Nilai } \\
\text { Pengukuran }\end{array}$ \\
\hline 1 & Jumlah item berlebih (commission) & 37 \\
2 & Tingkat item berlebih & $1.49 \%$ \\
3 & Jumlah item yang hilang (omission) & 17 \\
4 & Tingkat item yang hilang & $0.69 \%$ \\
\hline
\end{tabular}

sampai padat. Hasil pengecekan kelengkapan secara visual pada wilayah penelitian tersaji pada Tabel 2 .

\section{Deteksi kelengkapan secara otomatis}

Deteksi kesalahan dan evaluasi kualitas dilakukan pada layer bangunan dataset RBI menggunakan geoprocessing tools evaluasi kelengkapan. Deteksi menggunakan geoprocessing tools dilakukan dengan empat skenario berdasarkan data pembanding dan matching option. Skenario ini bertujuan untuk mencari pilihan model tools terbaik untuk pengembangan otomasi pengecekan kelengkapan. Skenario didasarkan pada bentuk data pembanding (poligon dan titik), operasi pencocokan, dan operasi join.

Dalam operasi pencocokan digunakan pilihan Intersect dan Have Their Center In. Operasi pencocokan Have Their Center In menggunakan radius $2,5 \mathrm{~m}$, dengan radius ini diharapkan obyek yang berpasangan adalah benar-benar obyek yang berlokasi sama. Operasi pencocokan Intersect memberikan kelonggaran pada obyek, obyek yang berpasangan adalah obyek yang saling bertampalan. Operasi join menggunakan hubungan 1-m, penggunaan operasi join 1-m dimaksudkan agar obyek berpasangan lebih leluasa dikenali, hal ini diterapkan karena adanya perbedaan segmentasi obyek bangunan uji dan referensi. Hasil deteksi kelengkapan secara otomatis ini menghasilkan possibility of omission dan possibility of commission 
yang akan divalidasi secara visual untuk menghasilkan omission dan commission yang fix.

Ada empat skenario yang diterapkan untuk mendapatkan hasil deteksi otomatis yaitu poligonpoligon dengan matching operation "Have Their Center In", poligon-titik dengan matching operation Have Their Center In (radius 2,5 meter), poligonpoligon dengan matching operation intersect, dan poligon-titik dengan matching operation intersect. Hasil deteksi otomatis dengan empat skenario menggunakan tools geoprocessing tools evaluasi kelengkapan adalah sebagai berikut:

Tabel 3. Hasil deteksi otomatis dengan opsi operasi

\begin{tabular}{|c|c|c|c|c|}
\hline $\begin{array}{c}\text { Ske- } \\
\text { nari } \\
0\end{array}$ & $\begin{array}{c}\text { Data Uji- } \\
\text { Pemban- } \\
\text { ding }\end{array}$ & $\begin{array}{l}\text { Join } \\
\text { Opera } \\
\text { tion }\end{array}$ & $\begin{array}{l}\text { Matching } \\
\text { Operation }\end{array}$ & $\begin{array}{l}\text { Hasil (Jumlah item } \\
\text { possibility) }\end{array}$ \\
\hline 1 & $\begin{array}{l}\text { Poligon- } \\
\text { Poligon }\end{array}$ & $1-m$ & $\begin{array}{l}\text { Have Their } \\
\text { Center In }\end{array}$ & $\begin{array}{c}\text { Commission: } 47 \\
\text { Omission: } 47\end{array}$ \\
\hline 2 & $\begin{array}{l}\text { Poligon- } \\
\text { Titik }\end{array}$ & $1-m$ & $\begin{array}{c}\text { Have Their } \\
\text { Center In } \\
\text { (radius } \\
2,5 \mathrm{~m})\end{array}$ & $\begin{array}{c}\text { Commission: } 242 \\
\text { Omission: } 17\end{array}$ \\
\hline 3 & $\begin{array}{l}\text { Poligon- } \\
\text { Poligon }\end{array}$ & $1-m$ & Intersect & $\begin{array}{c}\text { Commission: } 33 \\
\text { Omission: } 19\end{array}$ \\
\hline 4 & $\begin{array}{l}\text { Poligon- } \\
\text { Titik }\end{array}$ & $1-m$ & Intersect & $\begin{array}{c}\text { Commission:242 } \\
\text { Omission:17 }\end{array}$ \\
\hline
\end{tabular}

Skenario 1 mendeteksi 47 item berlebih dengan 10 item merupakan false commission dan mendeteksi 47 item yang hilang dengan 30 item merupakan false omission. Kesalahan deteksi ini disebabkan oleh obyek bangunan yang berbentuk $U$ atau $L$ sehingga titik tengah berada di luar poligon bangunan. Pada operasi pencocokan menggunakan Have Their Center In, unsur join tidak menemukan pasangan pada poligon referensi sehingga menyebabkan bangunan terdeteksi sebagai item yang hilang atau omission (Gambar 4a). False commission terjadi pada kasus perbedaan ploting dan digitasi terhadap obyek bangunan (Gambar 4b) sehingga menyebabkan bangunan terdeteksi sebagai item berlebih.

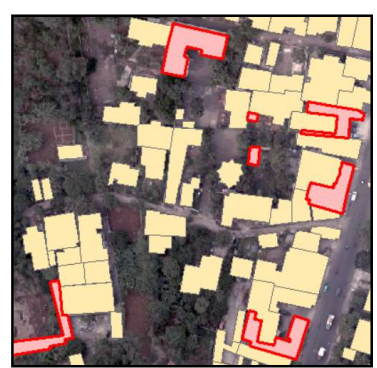

(a) (b)

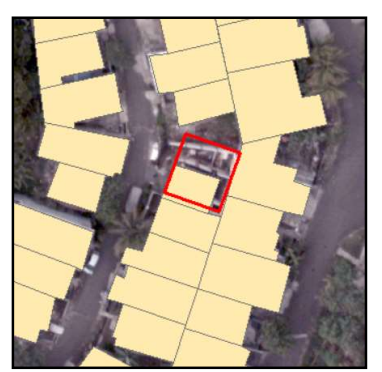

Gambar 4. Hasil false omission (a) dan false commission (b) pada skenario 1

Skenario 2 menggunakan data pembanding berupa titik dan menerapkan matching operation: Have Their Center In dengan radius 2,5 m dengan pola realasi 1-m. Hasil deteksi sejumlah 242 item berlebih dengan jumlah true commission sebanyak 16 item. Hal ini disebabkan operasi pencocokan menggunakan titik pusat menyebabkan unsur join berupa titik tidak selalu dapat berpasangan dengan titik tengah obyek target dan menyebabkan false commission yang cukup banyak (lihat Gambar 5a). Deteksi item yang hilang pada skenario ini sejumlah 17 item dengan 1 item merupakan false omission. Hal ini disebabkan karena posisi titik referensi tidak selalu berada tepat pada poligon data uji (Gambar 5b).

Skenario 3 menggunakan data pembanding poligon dan menerapkan matching operation:

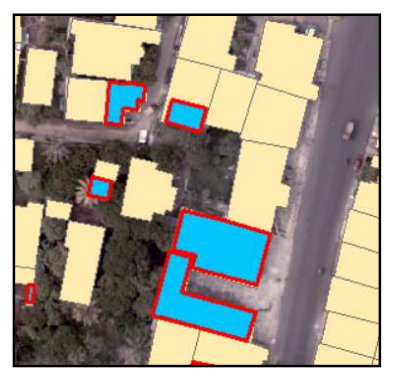

(a)

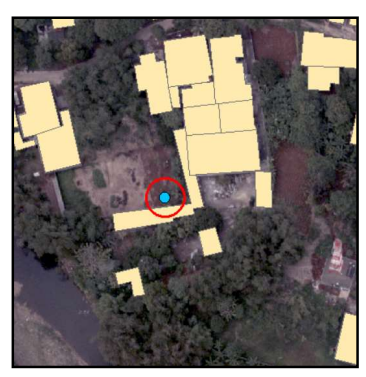

(b)
Gambar 5. Hasil false omission (a) dan false commission (b) pada skenario 2

intersect. Hasil yang diperoleh adalah 33 commission dan 19 omission. Dari 33 item commission, terdapat 4 item misdetection, hal ini disebabkan obyek bangunan yang seharusnya merupakan item berlebih masih bersentuhan dengan poligon referensi disebelahnya sehingga dianggap bukan kesalahan commission (lihat Gambar 6a). Hal yang sama terjadi juga pada deteksi obyek yang hilang, 
dari 19 item omission, 2 item obyek merupakan misdetection/tidak terdeteksi sebagai omission, hal ini disebabkan karena obyek uji masih bersinggungan dengan obyek referensi (Gambar 6b). Penerapan aturan intersect dengan relasi 1-m kurang cocok untuk mendeteksi omission dan commission pada lokasi obyek rapat.

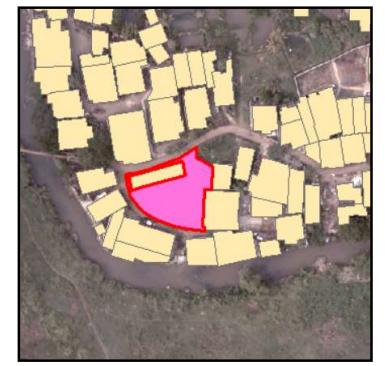

(a)

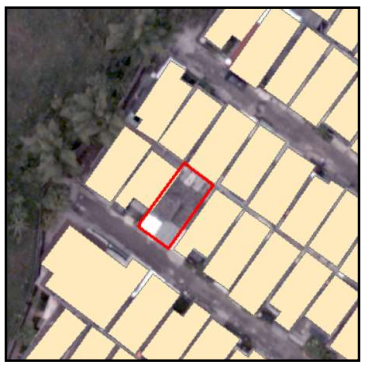

(b)
Gambar 4. Hasil false omission (a) dan false commission (b) pada skenario 3

Skenario 4 menerapkan operasi pencocokan intersect pada data pembanding yang berupa titik. Hasil skenario 4 mampu mendeteksi commission sejumlah 242 item dengan true commission sebanyak 16 item, misdetection 1 item dan false commission sebanyak 225 item. Kesalahan deteksi pada skenario ini disebabkan oleh titik bangunan referensi tidak bersentuhan dengan poligon data uji, hal ini terjadi karena adanya segmentasi pada boundary bangunan (Gambar 7a). Hasil deteksi omission diperoleh sebanyak 17 item dengan 1 item merupakan false omission dan 1 item misdetection, hal ini disebabkan karena titik referensi masih berada pada radius $2,5 \mathrm{~m}$ sehingga tidak terdeteksi sebagai omission (Gambar 7b).

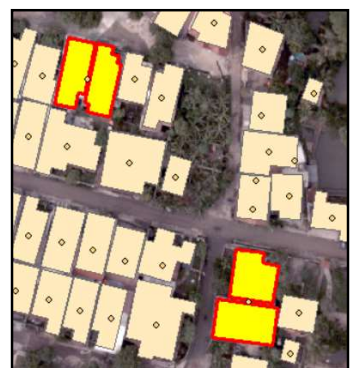

(a)

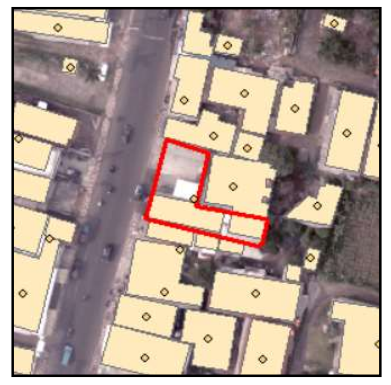

(b)
Gambar 7. Hasil misdetection pada commission (a) dan misdetection pada omission skenario 4

Hasil yang diperoleh dari ke empat skenario pendekatan deteksi otomatis diatas tidak sama dengan hasil deteksi secara manual (visual). Masing masing pendekatan memiliki kesalahan deteksi dengan nilai prosentase berbeda. Apabila hasil deteksi visual digunakan sebagai acuan, maka diperoleh perbandingan seperti disajikan pada Tabel 4. Hasil ini menggambarkan kemampuan tools deteksi kelengkapan yang mampu mendeteksi kesalahan omission dan commission, namun masih terdapat beberapa kesalahan deteksi yang disebabkan oleh kondisi data uji dan data pembanding.

Tabel 4. Perbandingan true commission- true omission berdasarkan visual check dan populasi data

\begin{tabular}{ccccc}
\hline $\begin{array}{c}\text { Ske- } \\
\text { nario }\end{array}$ & $\begin{array}{c}\text { True } \\
\text { Com. }\end{array}$ & $\begin{array}{c}\text { False } \\
\text { Com. }\end{array}$ & True Om. & False Om. \\
\hline 1 & 37 & 10 & 17 & 30 \\
2 & 16 & 226 & 15 & 2 \\
3 & 29 & 4 & 15 & 4 \\
4 & 16 & 226 & 15 & 2 \\
\hline
\end{tabular}

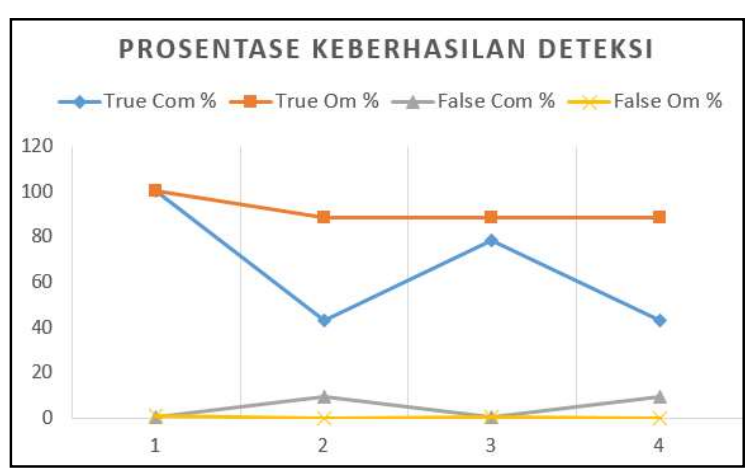

Gambar 8. Tingkat keberhasilan deteksi otomatis pada 4 skenario

Dari Gambar 8 dapat disimpulkan bahwa skenario evaluasi kualitas menggunakan data pembanding poligon dapat menghasilkan true commission dan true omission yang baik dengan kesalahan deteksi minimum dibandingkan dengan menggunakan data pembanding titik (radius $2.5 \mathrm{~m}$ ). Semua metode pencocokan menghasilkan false detection, sehingga perlu dilakukan proses validasi visual setelah proses deteksi secara otomatis. Berdasarkan hasil diatas, dapat disimpukan bahwa pemanfaatan tools otomasi menggunakan data pembanding secara otomatis belum dapat dilakukan secara full otomastis karena masih ditemukan false detection pada data hasil evaluasi kualitas. 


\section{Evaluasi Kelengkapan Semi Otomatis}

Penggunaan data pembanding merupakan persyaratan mutlak untuk menjalankan prosedur evaluasi kelengkapan secara otomatis. Data pembanding dapat berupa poligon maupun titik. Permasalahannya adalah tidak tersedianya data pembanding yang representatif untuk peta skala besar kecuali data dasarnya sendiri berupa foto udara. Percobaan menggunakan tools yang diotomasi masih perlu dioptimalkan agar tools tersebut dapat digunakan secara full otomatis.

$\mathrm{Hal}$ ini memunculkan gagasan untuk menjalankan prosedur semi otomatis dalam evaluasi kelengkapan (lihat Gambar 9). Prosedur ini

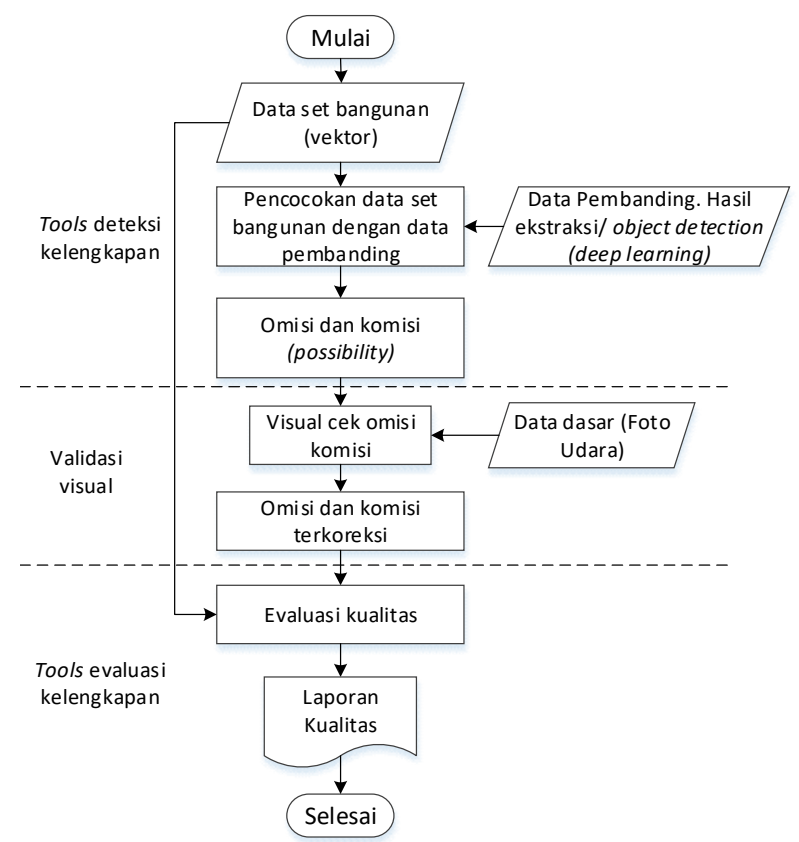

Gambar 5. Rekomendasi alur proses evaluasi kualitas kelengkapan semi otomatis layer bangunan

menggabungkan operasi otomatis menggunakan geoprocessing tools dan operasi manual dalam pengambilan keputusan secara visual. Operasi otomatis yang dijalankan adalah operasi deteksi kelengkapan berdasarkan data pembanding yang diperoleh dari proses ekstraksi data secara otomatis seperti object detection dengan deep learning. Tahap pertama dalam prosedur semi otomatis adalah mendeteksi obyek yang menjadi possibility error secara otomatis, tahap kedua melakukan validasi obyek kesalahan secara visual dan tahap ketiga melakukan kalkulasi kualitas secara otomatis. Berikut ini adalah diagram alir proses evaluasi kualitas kelengkapan secara semi otomatis.

Berdasarkan ketersediaan data referensi dan percobaan tools otomasi diatas maka untuk mendapatkan error rate, digunakan pendekatan semi otomatis. Pendekatan ini dapat dibagi menjadi 3 (tiga) tahap yaitu :

Pertama, adalah deteksi kelengkapan otomatis. Tahap ini menggunakan data pembanding berupa point vektor bangunan. Data bangunan point diperoleh dari konversi bounding-box hasil object detection pada foto udara yang diolah menggunakan teknik deep learning menggunakan model single shot detection (SSD) (Liu dkk., 2015). Metode deteksi kelengkapan otomatis adalah pencocokan dataset obyek vektor bangunan pada data uji dengan objek vektor (point) data pembanding. Dataset dinyatakan commission jika setelah dibandingkan diketahui obyek pada dataset bangunan uji lebih banyak dibanding dengan obyek pembanding. Dan sebaliknya dataset dinyatakan omission jika obyek pada dataset bangunan kekurangan dibanding dengan obyek pembanding. Metode perbandingan antara dataset bangunan data uji dengan dataset pembanding adalah dengan pendekatan spatial join dan fungsi select. Karena data pembanding bukan merupakan data dengan kualitas yang sudah teruji maka hasil omission dan commission dianggap sebagai obyek kemungkinan yang akan dilakukan pengecekan kembali pada tahap selanjutnya.

Kedua, adalah validasi visual. Tahap ini adalah tahap pengecekan omission dan commission secara visual. Visual cek dilakukan hanya pada possibility of omission dan commission secara visual diatas foto udara sebagai referensi. Pada tahap ini sangat mengandalkan kemampuan intepretasi foto udara dan pengetahuan lokal reviewer. Data pengecekan lapangan terhadap obyek possibility akan sangat direkomendasikan. Obyek false omission dan false commission akan dihapus sehingga menghasilkan obyek omission dan commission terkoreksi.

Ketiga, adalah evaluasi kualitas otomatis. Evaluasi kualitas adalah melakukan kalkulasi kelengkapan dimana kegiatan ini menilai sejauh mana konten data sesuai dengan dunia nyata. 
Batasan evaluasi kualitas kelengkapan sesuai dengan cakupan dataset dan tingkat skala yang diperlukan. Hasil yang diperoleh pada tahap ini adalah tingkat item berlebih (rate of excess items) dan tingkat item yang tidak ada (rate of missing items).

\section{PENUTUP}

\section{Simpulan}

Berdasarkan hasil dan pembahasan pendekatan evaluasi kualitas pada penelitian ini dapat diambil kesimpulan diantaranya:

1. Pendekatan evaluasi kualitas kelengkapan dapat dilakukan menggunakan analisis pencocokan antara data uji dan data pembanding dengan menentukan parameter matching operation dan join operation.

2. Pembangunan tools deteksi kelengkapan menggunakan teknik pencocokan memerlukan parameter operasi pencocokan. Hasil operasi pencocokan dengan "intersect" dan "Have Their Center In" berpengaruh pada data poligon, sedangkan untuk data pembanding berupa titik, kedua pilihan matching operation menghasilkan nilai yang sama.

3. Skenario evaluasi kualitas menggunakan data pembanding poligon dapat menghasilkan true commission dan true omission yang lebih baik dibandingkan dengan menggunakan data pembanding point dengan radius $2.5 \mathrm{~m}$.

4. Pendekatan metode pencocokan memiliki kesalahan deteksi omission dan commission dengan prosentase berbeda, sehingga masih perlu dilakukan proses validasi setelah dilakukan deteksi secara otomatis.

5. Berdasarkan hasil penelitian diatas, pengembangan tools otomasi menggunakan data pembanding secara otomatis belum dapat dilakukan secara full otomastis.

6. Prosedur untuk evaluasi kualitas yang dapat dijalankan untuk percepatan adalah prosedur evaluasi kualitas semi otomatis dengan tahapan deteksi possibility error otomatis, validasi visual dan kalkulasi kualitas otomatis.

\section{Saran}

Berdasarkan kekurangan dan keterbatasan dalam penelitian ini, saran yang dapat disampaikan diantaranya:

1. Agar metode pencocokan dapat digunakan dalam mendukung percepatan evaluasi kualitas kelengkapan secara full otomatis, maka perlu dikembangkan tools deteksi yang lebih akurat berbasis GIS maupun machine learning.

2. Untuk memperoleh omission dan commission yang lebih akurat dalam evaluasi kelengkapan, dapat diperdalam pada parameter maltching operation.

\section{Ucapan Terima Kasih}

Terima kasih kepada Badan Informasi Geospasial atas bantuan informasi dan data yang digunakan dalam penelitian ini. Terimakasih disampaikan juga kepada Program studi Magister Geomatika, Universitas Gadjah Mada yang memfasilitasi terlaksananya penelitian ini, serta semua pihak yang memberikan masukan konstruktif terhadap tulisan ini.

\section{DAFTAR PUSTAKA}

Ahmed, Z. (2020), Quality Control and Quality Assurance in GIS Database and Applications, GIS Consultant - Ain Shams University.

Badan Informasi Geospasial (2020), Spesifikasi Produk Data Basisdata Geospasial Nasional Indonesia, Vol.1, No.April, hal. 7-8.

Badan Standar Nasional Indonesia (2015), SNI/ISO 19157:2015 Informasi Geografis - Kualitas Data.

Brovelli, M.A. dan Zamboni, G. (2018), "A New Method for the Assessment of Spatial Accuracy and Completeness of OpenStreetMap Building Footprints", ISPRS International Journal of Geo-Information, Vol.7, No.8, hal. 289. http://doi.org/10.3390/ijgi7080289.

Devillers, R., Bédard, Y., Jeansoulin, R. dan Moulin, B. (2007), "Towards Spatial Data Quality Information Analysis Tools for Experts Assessing the Fitness for Use of Spatial Data", International Journal of Geographical Information Science, Vol.21, No.3, hal. 261-282. http://doi.org/10.1080/13658810600911879. 
Dobesova, Z. (2013), "Strengths and Weaknesses in Data Flow Diagrams in GIS", Proceedings - 2013, hal. 803807, http://doi.org/10.1109/CSA.2013.192.

Jakobsson, Mäkelä, Henriksson, Tsoulos, L., Beare, M. dan J, M. (2010), Implementing Quality in Spatial Data Infrastructures - Introducing Building Blocks of Quality Web Services,.

Kemenkumham RI (2020), Peraturan Presiden Nomor 18 Tahun 2020 Tentang Rencana Pembangunan Jangka Menengah Nasional Tahun 2020-2024 Kemenkumham RI,.

Liu, W., Anguelov, D., Erhan, D., Szegedy, C., Reed, S., Fu, C.-Y. dan Berg, A.C. (2015), "SSD: Single Shot MultiBox Detector", Computer Vision, Lecture Notes in Computer Science, Eds.: Leibe, B., Matas, J., Sebe, N., dan Welling, M., Springer International Publishing, Cham, hal. 21-37, http://doi.org/10.1007/978-3-31946448-0_2.

Perdana, A., Ginanjar, A., Mersariany, N. dan Mayasari, R. (2012), "Model Builder untuk Pembentukan Basisdata Nama Rupabumi Guna", Paper Konferensi FIT ISI, hal. 0-4, http://doi.org/10.13140/2.1.2585.5363.

Razniewski, S. dan Nutt, W. (2013), "Assessing the Completeness of Geographical Data", Big Data, Lecture Notes in Computer Science, Eds.: Gottlob, G., Grasso, G., Olteanu, D., dan Schallhart, C., Springer, Berlin, Heidelberg, hal. 228-237, http://doi.org/10.1007/978-3-642-39467-6_21.

Schaller, J. dan Mattos, C. (2009), "ArcGIS ModelBuilder Applications for Landscape Development Planning in the Region of Munich, Bavaria", Peer Reviewed Proceedings of the Digital Landscape Architecture Conference, Valletta, Malta, Malta, hal. 127-136,.

Shi, W., Bo, W. dan Stein, A. (2015), Uncertainty Modelling and Quality Control for Spatial Data, CRC Press.

Wan, Y., Shi, W., Gao, L., Chen, P. dan Hua, Y. (2015), "A General Framework for Spatial Data Inspection and Assessment", Earth Science Informatics, Vol.8, No.4, hal. 919-935. http://doi.org/10.1007/s12145-0140196-9.

Xavier, E., Ariza-Lopez, F. dan Ureña-Camara, M. (2016), "A Survey of Measures and Methods for Matching Geospatial Vector Datasets", ACM Computing Surveys,
Vol.49, No.2, hal. 1-34. http://doi.org/10.1145/2963147. 